\title{
PERFIS HEMATOLÓGICOS, BIOQUÍMICOS E PROTEÍNA PLASMÁTICA TOTAL DE GATOS INFECTADOS COM O VÍRUS DA LEUCEMIA FELINA
}

\author{
(Hematology, serum biochemistry and total plasma protein values of feline leukemia \\ virus infected cats)
}

\author{
Rafaela Furioso Ferreira ${ }^{1}$, Rosangela Locatelli Dittrich ${ }^{1}$, Patrícia Yukiko Montaño ${ }^{1}$, Kamilla \\ Andressa Leite da Silva ${ }^{1}$, Ana Laura Pinto D’Amico Fam² \\ 1'Universidade Federal do Paraná, ${ }^{2}$ Universidade Tuiuti do Paraná. \\ *Correspondência: roslocdi@ufpr.br
}

RESUMO: A leucemia viral felina (FeLV) é causada por um retrovírus $E$ pode provocar várias alterações no organismo, como distúrbios de proliferação celular (linfoma ou doenças mieloproliferativas) e de supressão celular (imunodeficiência e mielosupressão). Considerando a importância dos resultados laboratoriais no diagnóstico, avaliação clínica e determinação do prognóstico de gatos infectados, os objetivos do estudo foram descrever as alterações hematológicas, bioquímicas e de proteína plasmática total de gatos infectados com o vírus da leucemia. Foram coletadas amostras de sangue de 48 gatos infectados com FeLV e avaliados os valores de hematócrito, hemoglobina, contagem de hemácias, leucócitos, plaquetas, análise citomorfológica e contagem diferencial de leucócitos e proteína plasmática total. Os valores de alanina aminotransferase (ALT), gama-glutamiltransferase (GGT), ureia e creatinina também foram avaliados. A linfopenia foi a alteração hematológica mais comum, em $31,25 \%$ dos gatos, seguida pela presença de linfócitos reativos ou atípicos (27,1\%). Houve anemia em $16,66 \%$ dos gatos; leucocitose em 16,66\%; leucopenia em 14,58\%; linfocitose em $8,33 \%$, monocitose em $14,58 \%$, eosinofilia em $4,17 \%$, neutrofilia em $16,66 \%$, neutropenia em $16,66 \%$, desvio nuclear de neutrófilos à esquerda em $14,58 \%$ e presença de neutrófilos tóxicos em 16,66\%. No perfil bioquímico, em 3,16\% dos animais verificou-se azotemia; no perfil hepático, as alterações foram: aumento da GGT em 18,52\%, aumento da ALT em 33,33\% e aumento de ambas em 7,40\%. No presente estudo, constatou-se que em $78,95 \%$ dos animais houve alguma alteração no hemograma. O estudo ressalta a importância do hemograma no diagnóstico, monitoramento e determinação do prognóstico de gatos infectados com FeLV.

Palavras-chave: FeLV; hematologia; perfil renal, perfil hepático

ABSTRACT: Feline leukemia virus (FeLV) is a retrovirus (genus Gammaretrovirus) that can cause various disorders in cats, such as proliferative disorders (lymphoma or myeloproliferative diseases) and cell suppression (immunodeficiency and myelosuppression). Considering the importance of laboratory results in the diagnosis, clinical evaluation and prognosis of infected cats, the objectives of this study were to describe the hematological, biochemical and total plasma protein profiles of cats infected with feline leukemia virus. Blood samples were collected from $48 \mathrm{FeLV}$-infected cats and were performed hematocrit, hemoglobin, red blood cell count, leukocyte count, platelet count, cytomorphological analysis, and total leukocyte count and total plasma protein. Values of alanine aminotransferase (ALT), 
gamma-glutamyltransferase (GGT), urea and creatinine were also evaluated. Lymphopenia was the most common hematological alteration in $31.25 \%$ of cats, followed by the presence of reactive or atypical lymphocytes (27.1\%). Anemia was reported in $16.66 \%$ of infected cats; leukocytosis in $16.66 \%$; leucopenia in $14.58 \%$; lymphocytosis in $8.33 \%$, monocytosis in $14.58 \%$, eosinophilia in $4.17 \%$, neutrophilia in $16.66 \%$, neutropenia in $16.66 \%$, nuclear neutrophil deviation to the left in $14.58 \%$ and presence of neutrophils toxic in $16.66 \%$. As for the biochemical profile, $3.16 \%$ of the animals had azotemia; for the liver enzymes, changes were: increase in GGT in $18.52 \%$, increase in ALT in $33.33 \%$, and increase of both in $7.40 \%$. In the present study, it was found that in $78.95 \%$ of the animals there was some change in the blood count. The study emphasizes the importance of the hemogram in the diagnosis, monitoring and determination of the prognosis FeLV infected cats.

Key Words: FeLV; liver enzymes; kidney enzymes

\section{INTRODUÇÃO}

A leucemia viral felina (FeLV),
causada por um vírus da família Retroviridae, gênero Gammaretrovirus, é uma das doenças infecciosas de maior importância na medicina felina. A FeLV já foi considerada a doença com maior número de mortes e síndromes clínicas do que quaisquer outros agentes em gatos (HARTMANN, 2012).

A transmissão da FeLV entre gatos suscetíveis ocorre mais comumente via oronasal, através do contato com secreções, ou por mordeduras. A maioria dos gatos são infectados em interações sociais, como ao partilhar o recipiente de água $e$ comida, utilizar a mesma caixa de areia, bem como através de grooming mútuo ou brigas entre os felinos (COSTA; NORSWORTHY, 2010; LEVY; CRAWFORD, 2010). O desfecho da infecção pelo FeLV depende da idade e do status imune do animal, carga viral, patogenia do vírus e pressão de infecção (COSTA; NORSWORTHY, 2010). Atualmente, a infecção da FeLV pode ser classificada em quatro estágios: abortiva, regressiva, progressiva e focal ou atípica. (HOFMANN-LEHMANN et al., 2008; HARTMANN, 2012).
A infecção pelo FeLV tem efeitos paradoxais, podendo causar tanto doenças de proliferação celular (linfoma ou doenças mieloproliferativas) como também supressão celular (imunodeficiência e mielosupressão). (ANDERSON et. al, 1971; TORRES et. al, 2005). Conforme ressalta Hartmann (2012), apesar do vírus da leucemia felina ser nomeado a partir de neoplasia, a maioria dos gatos infectados são levados ao veterinário não por neoplasias, mas por anemia ou imunossupressão. A supressão da medula óssea é a síndrome clínica mais comumente associada ao FeLV, e alguns estudos relatam anemia, neutropenia, anormalidades plaquetárias, pancitopenia e presença de blastos (LEVY; CRAWFORD, 2010). No Brasil a infecção pelo vírus é elevada e crescente (SOBRINHO et al., 2011), possivelmente causando alterações similares, mas as informações são escassas.

Considerando a importância dos achados laboratoriais na avaliação clínica de gatos infectados pelo vírus da leucemia viral felina, o objetivo desse estudo foi determinar os parâmetros hematológicos, bioquímicos e proteína plasmática total (PPT) de gatos infectados por FeLV da cidade de Curitiba, Paraná. 


\section{MATERIAL E METODOS}

Foram utilizados 48 gatos (23 fêmeas e 25 machos) da cidade de Curitiba, Paraná, com idades entre 5 meses e 10 anos. O diagnóstico foi realizado por ensaio de imunoabsorção enzimática (ELISA) comercial para detecção do antígeno p27. O hemograma foi realizado com a determinação do hematócrito (técnica do microhematócrito) e a contagem de hemácias, leucócitos, plaquetas e determinação da hemoglobina no contador de células sanguíneas Mindray ${ }^{\circledR}$, modelo BC 2800 VET. A contagem diferencial de leucócitos foi realizada na extensão sanguínea corada. A determinação da proteína plasmática total foi realizada por refratometria. O perfil bioquímico renal foi analisado em 32 gatos com a determinação da ureia e creatinina e o perfil bioquímico hepático foi analisado em 27 gatos através da determinação da gama-glutamiltransferase (GGT) e alanina aminotransferase (ALT), realizados no analisador automático Mindray ${ }^{\circledR}$, modelo BS-200.

\section{RESULTADOS}

Os resultados obtidos roram
comparados com os ralores
hematológicos de referência
estabelecidos por Weiss e Wardrop
(2010) e os bioquímicos por Kaneko
(2008). A linfopenia foi a alteração
hematológica mais comum, em $31,25 \%$
dos gatos, seguida pela presença de
linfócitos reativos ou atípicos $(27,1 \%)$. A
anemia foi observada em $16,66 \%$ dos
gatos infectados; leucocitose em
$16,66 \%$; leucopenia em $14,58 \%$;
linfocitose em $8,33 \%$, monocitose em
$14,58 \%$, eosinofilia em $4,17 \%$, neutrofilia
em $16,66 \%$, neutropenia em $16,66 \%$,
desvio nuclear de neutrófilos à esquerda
em $14,58 \%$ e presença de neutrófilos
tóxicos em 16,66\%. Em apenas um

animal houve alteração na PPT (diminuída). A avaliação dos trombócitos foi limitada pela presença de agregados plaquetários em grande quantidade das amostras avaliadas. Contudo, nos 12 animais em que foi possível realizar a análise, em 6 (50\%) foi observada trombocitopenia e $3(25 \%)$ trombocitose. Quanto ao perfil bioquímico, em 3,16\% dos animais existiu alteração em perfil renal (aumento de ureia e creatinina); no perfil hepático, houve aumento da GGT em $18,52 \%$, aumento da ALT em $33,33 \%$ e aumento de ambas em $7,40 \%$.

\section{DISCUSSÃO}

A prevalência da FeLV é variável nos diversos estados do Brasil, com índices de 0,33\% a 6,2\% em São Paulo (SOBRINHO et al., 2011; JUNQUEIRAJORGE, 2005) até 47,5\% em Minas Gerais (COELHO et al., 2008). A FeLV é comum nos gatos de Curitiba, Paraná, estando presente em $28,9 \%$ das amostras em estudo realizado por Montaño (2014). Assim, percebe-se que a prevalência da FeLV no Brasil está significativamente acima da prevalência estabelecida como mundial, de $5 \%$ (COSTA; NORSWORTHY, 2010), ressaltando a necessidade de dados acerca da doença no país.

No presente estudo, a alteração hematológica mais comum foi a linfopenia $(31,25 \%)$, podendo estar associada ou não a leucopenia, e estando a anemia presente apenas em $16,66 \%$ dos animais. A linfopenia pode estar associada a infecções recentes ou a imunossupressão a longo prazo associada principalmente a diminuição dos linfócitos CD4+ (HOFMANNLEHMANN et al., 1997). Nos Estados Unidos, a anemia não regenerativa moderada é descrita como o achado hematológico mais frequente pela infecção do FeLV (SHELTON; LINENBERGER, 1995). Na Espanha, Arjona et al. (2000) verificaram que a 
neutropenia foi a alteração hematológica mais comum. No Brasil, as alterações hematológicas e bioquímicas causadas pela cepa viral circulante são pouco relatadas.

A presença de linfócitos reativos também foi significativa. Os linfócitos reativos ocorrem por estímulo antigênico, sendo achados frequentes na estimulação antigênica crônica associada a hiperplasia dos linfonodos periféricos na FeLV. Também pode ocorrer a auto ativação de linfócitos, considerada um reflexo na falha da regulação natural (supressão) destas células. Os linfócitos atípicos sugerem neoplasia linfoide, e são dificilmente diferenciados de linfócitos reativos podendo ser realizada imunotipagem para estudo mais aprofundado (WEISS; WARDROP, 2010).

A trombocitopenia foi encontrada em metade das amostras em que foi possível realizar a análise. O FeLV é a causa mais comum de trombocitopenia em gatos (LEVY; CRAWFORD, 2010). A trombocitopenia pode ocorrer como secundária a mielosupressão ou por infiltração leucêmica, podendo converter-se em distúrbio de coagulação (HARTMANN, 2011). Também foi detectada trombocitose em $25 \%$ das amostras.

Não foi apontada significante alteração no perfil bioquímico renal de gatos infectados, resultado que corrobora com os achados de Arjona et. al (2000). Houve aumento da GGT em $18,52 \%$ dos animais, sugerindo colestase hepática e aumento da ALT em $33,33 \%$, sugerindo necrose hepática. Houve aumento de ambas em $7,40 \%$ dos gatos. Tais resultados corroboram com estudos de Gleich e Hartmann (2009), que apontaram aumento nos níveis séricos de ALT em $6 \%$ e GGT em 3\% comparando gatos infectados com FeLV ao grupo controle.

\section{CONCLUSÃO}

No presente estudo, constatou-se que em $78,95 \%$ dos animais houve alguma alteração no hemograma. A principal alteração hematológica foi a linfopenia; no exame bioquímico, a principal alteração foi o aumento da ALT, enzima sugestiva de necrose hepática. $O$ estudo ressalta a importância do hemograma no diagnóstico, monitoramento e determinação do prognóstico de gatos infectados com FeLV.

\section{REFERENCIAS}

ANDERSON, L.J.; JARRETT, W.F.H.; JARRETT, O. et al. Feline leukemiavirus infection of kittens: mortality associated with atrophy of the thymus and lymphoid depletion. Journal of National Cancer Institute. v. 47, 1971. p. $807-817$.

ARJONA, A.; ESCOLAR, E.; SOTO, I. et al. Seroepidemiological survey of infection by feline leukemia virus and immunodeficiency virus in Madrid and correlation with some clinical aspects. Journal of Clinical Microbiology. v. 38, 2000. p. 3448-3449.

COELHO, F.M. Naturally occurring feline leukemia virus subgroup $A$ and $B$ infections in urban domestic cats. Journal of General Virology, v.89, p.2799-2805, 2008.

COSTA, F. V A.., NORSWORTHY, G.D. Feline leukemia virus diseases. In: NORSWORTHY, G. D. (Ed). The Feline Patient. 4 ed. lowa: Wiley-Blackwell, 2010. p. 184-188.

GLEICH, S., HARTMANN, K. Hematology and serum biochemistry of feline immunodeficiency virus-infected and feline leukemia virus infected cats. Journal of Veterinary Internal Medicine. v. 23, n.3, 2009. p.552-558. 
HARTMANN, K. Clinical aspects of feline retroviruses: A review. Viruses, v.4, 2012. p.2684-2710

HOFMANN-LEHMANN,

R.; SHELTON, G.H., LINENBERGER, M.L. HOLZNAGEL, E.; OSSENT, P. et al. Parameters of disease progression in long-term experimental feline retrovirus (feline immunodeficiency virus and feline leukemia virus) infections: hematology, clinical chemistry, and lymphocyte subsets. Clinical and Diagnostic Laboratory Immunology. v. 4, 1997. p. 33-42.

HOFMANN-LEHMANN, R.; CATTORI, V.; TANDON, R. et al. How molecular methods change our views of FeLV infection and vaccination. Veterinary Immunology and Immunopathology, v.123, p.119-123. 2008.

HOOVER E. A., OLSEN R. G., HARDY W. D. JR. ET AL. Feline leukemia virus infection: age-related variation in response of cats to experimental infection. Journal of National Cancer Institute. v. 57. p. 365-369. 1976

JUNQUEIRA-JORGE, J. Estudo dos fatores de risco da leucemia viral felina no município de São Paulo. 2005. 43f. Tese (Mestrado em Ciências Veterinárias) -Universidade de São Paulo, Faculdade de Medicina Veterinária e Zootecnia. São Paulo, 2005.

KANEKO, J. J., HARVEY, J. W., BRUSS, M. L. Clinical Biochemestry of Domestic Animals. California: Elsevier. 2008. 928p.

LEVY, J. K., CRAWFORD, P. C. Feline Leukemia Virus. In: ETTINGER, S. J., Textbook of Veterinary Internal Medicine Expert Consult. 7 ed. St. Louis: Elsevier, 2010. Cap. 212, p. 935939

MONTAÑO, P. Y. Ocorrência De Coinfecções Em Gatos Domésticos Anêmicos E Não Anêmicos. 2014. 61p. Tese (Mestrado em Ciências
Veterinárias) - Setor de Ciências Agrárias, Universidade Federal do Paraná. Curitiba, 2014.

Hematologic abnormalities associated with retroviral infections in the cat. Seminary of Veterinary Medicine Surgery (Small Animals). v.10, 1995. p. 220-233. BRAGA, E. T. et al. orofrequência de felina e vírus da leucemia felina em gatos do município de araçatuba, são paulo. Brazilian Journal of Veterinary Research and Animal Science, v. 48, n. 5, p. 378-383, 2011.

TORRES, A.N., MATHIASON, C.K., HOOVER, E.A. Re-examination of feline leukemia virus: Host relationships using real-time PCR. Virology, v. 332, 2005. p. $272-283$.

WEISS, D.J.; WARDROP, K.J. Schalm's Veterinary Hematology. lowa: WileyBlackwell, 2010. 1232p.
SOBRINHO, L. S. V.; VIDES, J. P.; infecção pelo vírus da imunodeficiência 